\title{
Die Schweizerische Balint-Gesellschaft
}

\section{Monika Diethelm-Knoepfel}

Präsidentin

Korrespondenz:

Dr. med.

Monika Diethelm-Knoepfel

Wattstrasse 14

CH-9240 Uzwil

Tel. 0719559767

Fax 0719559769

monika.diethelmknoepfel@

hin.ch

www.balint.ch
Die Schweizerische Balint-Gesellschaft (SBG) wurde 1999 von einer Gruppe erfahrener Balint-Gruppenleiter gegründet. Sie hat sich folgende Zielsetzungen gegeben:

- Qualitätsförderung der Balint-Gruppenleitung in der Schweiz;

- Angebot entsprechender Ausbildungs-, Weiterbildungs- und Fortbildungsmöglichkeiten;

- Pflege des Kontakts zu Gesellschaften, die im Bereich der psychosomatischen und -sozialen Medizin sowie in verwandten Bereichen auf nationaler und internationaler Ebene tätig sind. gebote für Balint-Gruppenleiter. Ordentliche Mitglieder der SBG müssen eine anerkannte Weiterbildung zum Balint-Gruppenleiter sowie 10 Fortbildungsstunden pro Jahr nachweisen.

Balint-Gruppen werden in der Schweiz seit den späten 1960er Jahren nach dem vom Psychoanalytiker Michael Balint in Zusammenarbeit mit Hausärztinnen und Hausärzten entwickelten Modell angeboten. In Gruppensitzungen von meist 90 Minuten erzählt ein Teilnehmer von einem Patienten bzw. Klienten, und anschliessend erfolgt eine freie Diskussion, in welcher der Gruppenleiter vor allem Modera-

\section{Michael Balint hat sein Modell gemeinsam mit Hausärztinnen und Hausärzten entwickelt.}

Die Schweizerische Balint-Gesellschaft ist Mitglied der internationalen Balintföderation IBF. Unter der Schirmherrschaft der SBG werden jedes Jahr verschiedene Balint-Tagungen durchgeführt, die Gelegenheit bieten, die Balint-Gruppenarbeit kennenzulernen und diese Arbeitsweise intensiv zu erleben. Daneben bieten die Mitglieder der SBG kontinuierliche BalintGruppen in den meisten Gebieten der Schweiz an. Die SBG und die Leiterteams der von ihr anerkannten Balint-Tagungen organisieren zudem Fortbildungsan- torfunktion übernimmt. In der Diskussion gilt das Hauptinteresse der Beziehung zwischen Betreuer und Patient bzw. Klient. Diese Arbeitsweise hat sich in vielen Berufsgruppen bewährt, in denen Beziehungen wichtig sind, ausser im Gesundheitswesen auch bei Seelsorgern, Lehrern und Juristen.

Informationen über die SBG und die Balint-Arbeit in der Schweiz finden sich unter www.balint.ch. Anfragen nimmt die Präsidentin gerne entgegen.
In Gruppensitzungen erzählt ein Teilnehmer von einem Patienten bzw. Klienten, anschliessend folgt eine freie Diskussion.

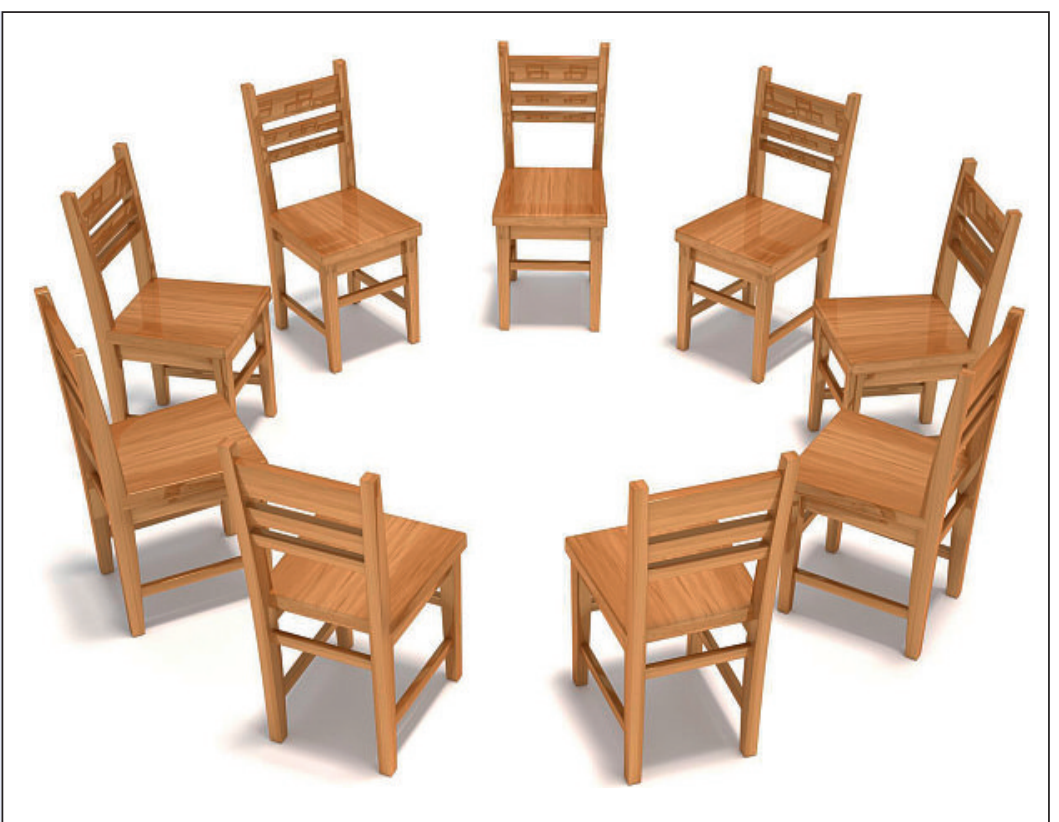

